\title{
Phyllodes tumor of the breast- Cytohistological study
}

\author{
Sweety Goyal ${ }^{1}$, Kamna Gupta ${ }^{2, *}$, Alok Mohan ${ }^{3}$, Anupam Varshney ${ }^{4}$, Veena K. Sharma ${ }^{5}$ \\ ${ }^{1}$ PG Junior Resident, ${ }^{2}$ Assistant Professor, ${ }^{3}$ Associate Professor, ${ }^{4}$ Professor, ${ }^{5}$ Professor \& Head, Dept. of Pathology, \\ Muzaffarnagar Medical College, Muzaffarnagar, Uttar Pradesh, India
}

*Corresponding Author:

Email: drkamnagupta09@gmail.com

Received: $30^{\text {th }}$ August, 2017

Accepted: $20^{\text {th }}$ November, 2017

\begin{abstract}
Introduction: Phyllodes tumor constitutes an uncommon group of mammary fibroepithelial neoplasm, having incidence of about $0.3 \%$ to $1 \%$ of breast tumors. The median age of occurrence of disease is 40 to 50 years. These tumors were first recognized by Muller, who used the term "cystosarcoma phyllodes" (phyllos = leaf, Greek). The differential diagnosis between phyllodes tumor $\&$ fibroadenoma and histological grading of phyllodes tumor is challenging.

Material and Methods: Retrospective data from cytology and histopathology record in pathology Department, Muzaffarnagar Medical College, Muzaffarnagar showed seven cases of phyllodes tumor. In all cases, Fine Needle Aspiration Cytology (FNAC) was initially performed and was further confirmed on histopathology.

Results: The age range of these patients was from 18 to 61 years. The size of the breast lesion ranged from $6 \times 5 \mathrm{cms}$ to $40 \times 30$ cms. Tumors were classified according to WHO grading system based on the degree of stromal cellularity and atypia, presence or absence of stromal overgrowth, mitotic count and nature of tumor margin. Out of seven cases, two cases of were reported as benign phyllodes tumor, four as borderline and one as malignant. Two cases recurred within one year, one was benign and other one was diagnosed as borderline.

Conclusion: Preoperative diagnosis and proper management is important in phyllodes tumor to minimize the recurrence and malignant potential. So, accurate diagnosis of phyllodes tumor is crucial so that they are effectively treated. Treatment include wide surgical excision with negative margins.
\end{abstract}

Keywords: Breast, Phyllodes, Fibroadenoma, Classification, Fibroepithelial neoplasm.

\section{Introduction}

Phyllodes tumor is the unusual fibroepithelial tumor of the breast, accounting for less than $1 \%$ of breast tumors. ${ }^{1-3}$ These are rare in early age and in elderly, women commonly affected are between 40-50 years of age. ${ }^{4,5}$ They have been classified into benign, borderline and malignant according to the World Health Organinization (WHO) classification ${ }^{6}$ based on various histological features like a) Stromal cellularity and atypia, b) Mitotic activity, c) Stromal overgrowth and d) Tumor margin appearance; but there is no clear cut single criteria thus their diagnosis depends on the constellation of various histologic parameters. Most of the tumors are benign in nature with local recurrence rate about $17 \%$ in benign phyllodes while in malignant phyllodes tumor, it is $27 \%$ and the risk of distant metastasis is upto $22 \%$ in malignant phyllodes tumors. ${ }^{6}$ On one end of spectrum, it simulate fibroadenoma because of having exaggerated intracanalicular structure and cleft like spaces while on other extreme of spectrum, it can be misdiagnosed as primary breast sarcoma due to its increased cellularity of stroma and atypia. ${ }^{7,8}$ Initially, the treatment was mastectomy which is now replaced by the breast conservative surgery i.e. the wide surgical excision along with negative surgical margins. ${ }^{4}$ Two aspects must be taken into account: the risk of distant metastasis and the sarcomatous progression from benign/borderline to malignant tumor.
We encountered seven cases during the last 11 years which had some interesting features like early age of presentation (18 years), its unusual large size (40x30 cms) and recurrence seen in benign as well as borderline phyllodes tumor, this prompted us to present these cases.

\section{Materials and Methods}

This is a retrospective study in which we studied FNAC and histopathology cases from archives of breast lesions at the Department of Pathology, Muzaffarnagar Medical College, Muzaffarnagar and found 7 cases of phyllodes tumor. Fine Needle Aspiration Cytology was initially performed in all cases which were further confirmed on histopathology.

\section{Results}

Seven cases, all females with age range from 18 to 60 years were retrieved from archives of pathology department (Table 1). Size of the breast lump ranged from $6 \times 5 \mathrm{cms}$ to $40 \times 30 \mathrm{cms}$ and there was no axillary lymphadenopathy. On cytology, smears were moderately to richly cellular, showing mainly stromal fragments with few epithelial cells (Fig. 1). Stromal fragments showed increased cellularity. Stromal cells were oval to spindle shaped with moderate amount of cytoplasm. Significant pleomorphism was seen in 
malignant tumor (Fig. 2). On cytology, out of these seven cases; four cases were diagnosed as benign phyllodes tumor, two as borderline and one case was reported as malignant phyllodes tumor. All these cases were subjected to histopathological examination. Grossly most of the phyllodes tumors were round to oval, sharply delineated \& lobulated. Size of the tumor varied from as small as $6 \times 5 \mathrm{cms}$ to as large as $40 \times 30$ $\mathrm{cms}$. On cut, tissue was gray- white in colour and there was presence of slit like spaces. In large tumor, areas of haemorrhage and necrosis were also seen.

On microscopic examination, low magnification showed leaf like fronds with interspersed clefting spaces (Fig. 3). On higher magnification, most of the tumor had increased stromal cellularity which varied from mildly increased cellularity in benign phyllodes to markedly increased cellularity of stroma in malignant tumor. In malignant phyllodes tumor, atypical stromal cells and mitotic activity was also seen (Fig 4, 5). Thus on histopathological examination, two benign tumors were diagnosed as borderline (Table 1), accounting for $71 \%$ of accuracy in diagnosing these cases on cytology in this study.

Local recurrence was seen in two patients within one year, one was benign and other was borderline. This indicate that histological classsification does not work well with the biological behaviour.

Table 1: Patient age, tumor diameter and cytohistological correlation of seven cases:

\begin{tabular}{|l|c|c|c|c|}
\hline Case & Patient age & Tumor diameter & Cytology & Histological Type \\
\hline I & $18 \mathrm{yr}$ & $9 \times 7 \times 3 \mathrm{cms}$ & Benign & Benign \\
\hline II & $37 \mathrm{yr}$ & $8.5 \times 8 \times 6 \mathrm{cms}$ & Malignant & Malignant \\
\hline III & $50 \mathrm{yr}$ & $16.5 \times 13 \times 10 \mathrm{cms}$ & Benign & Borderline \\
\hline IV & $60 \mathrm{yr}$ & $40 \times 30 \times 15 \mathrm{cms}$ & Benign & Borderline \\
\hline V & $21 \mathrm{yr}$ & $8 \times 5 \times 4 \mathrm{cms}$ & Benign & Benign \\
\hline VI & $36 \mathrm{yr}$ & $6 \times 5 \times 2 \mathrm{cms}$ & Borderline & Borderline \\
\hline VII & $50 \mathrm{yr}$ & $6 \times 5 \times 2 \mathrm{cms}$ & Borderline & Borderline \\
\hline
\end{tabular}

Table 2: Definitions of histologic parameters for evaluation of phyllodes tumors in core biopsy and excisional specimens: ${ }^{11,12}$

\begin{tabular}{|l|l|}
\hline Histologic Parameters & Definitions \\
\hline Mitotic activity & Evaluated in more cellular areas and quantified per 10 HPF (X40) \\
\hline Stromal overgrowth & $\begin{array}{l}\text { Stromal proliferation without accompanying epithelial elements in at } \\
\text { least 1 low- power field (X4) }\end{array}$ \\
\hline $\begin{array}{r}\text { Stromal cellularity } \\
\text { a) Mild }\end{array}$ & $\begin{array}{l}\text { Evaluated in the most cellular areas } \\
\text { Twice cellularity of normal perilobular stroma with evenly spaced } \\
\text { nuclei without overlapping } \\
\text { Intermediate in degree between mildly and markedly } \\
\text { b) Moderate } \\
\text { overlapping }\end{array}$ \\
\hline $\begin{array}{r}\text { Stromal atypia } \\
\text { a) Mild } \\
\text { b) Moderate } \\
\text { c) Marked }\end{array}$ & $\begin{array}{l}\text { Small, uniform nuclei, with absent or inconspicuous nucleoli } \\
\text { Intermediate in degree between mildly and markedly } \\
\text { Marked variation in nuclear size and shape, irregular nuclear } \\
\text { membrane, and prominent nucleoli }\end{array}$ \\
\hline Intratumoral heterogeneity & $\begin{array}{l}\text { Variability in structure and stromal cellularity or atypia in a single } \\
\text { tumor }\end{array}$ \\
\hline Infiltrative tumor margin & $\begin{array}{l}\text { Projections of tumor stroma into the peritumoral stroma or adipose } \\
\text { tissue }\end{array}$ \\
\hline Leaflike pattern & $\begin{array}{l}\text { Enhanced intracanalicular pattern, characterized by projection of } \\
\text { cellular stroma into epithelial lined clefts of cystic spaces }\end{array}$ \\
\hline Stromal fragmentation & $\begin{array}{l}\text { Stroma with epithelium at one or both ends of the biopsy fragment, } \\
\text { result of leaflike pattern in core biopsy specimen }\end{array}$ \\
\hline $\begin{array}{l}\text { Subepithelial stromal } \\
\text { condensation }\end{array}$ & Enhanced stromal cellularity adjacent to or underneath epithelium \\
\hline
\end{tabular}




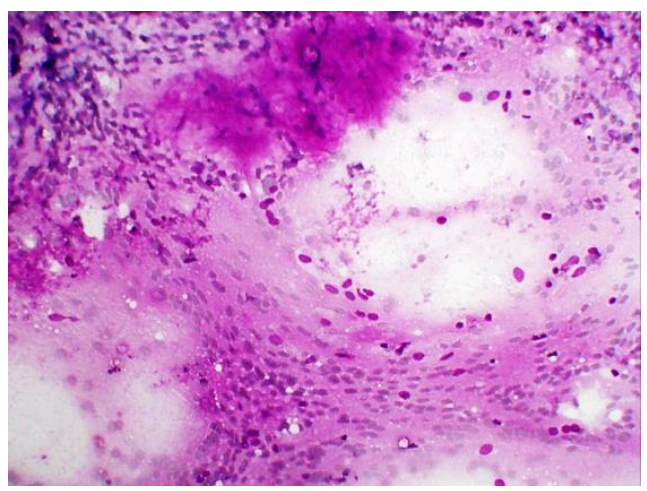

Fig. 1:

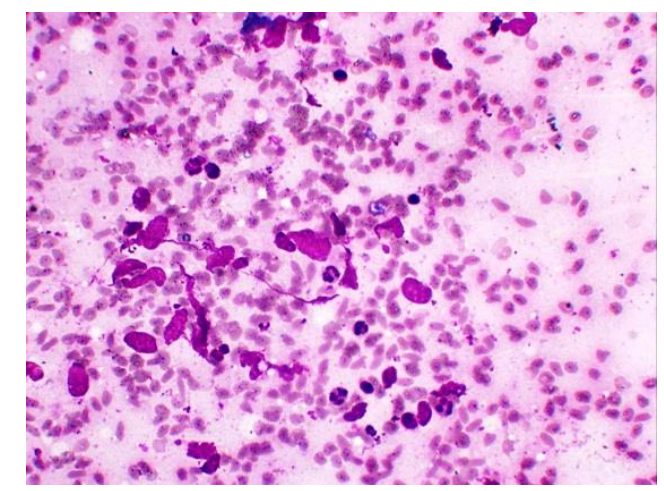

Fig. 2:

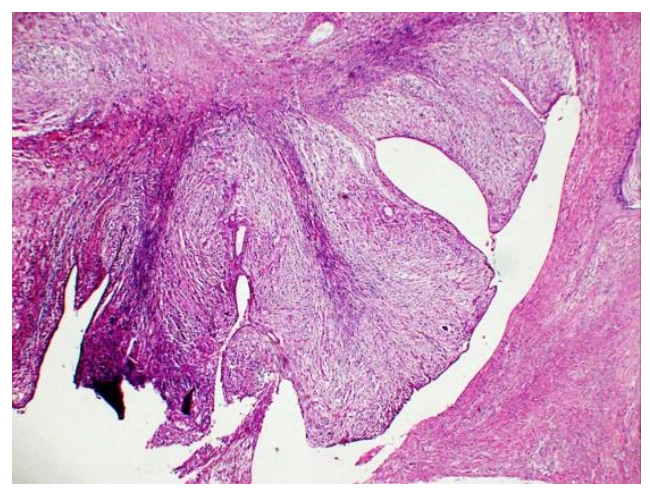

Fig. 3:

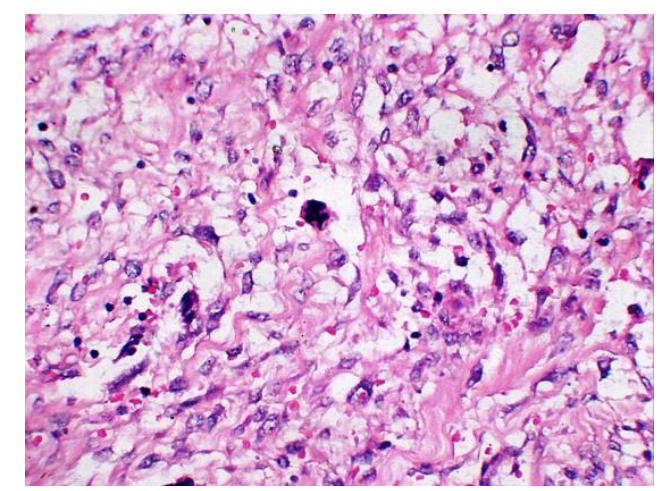

Fig. 4:

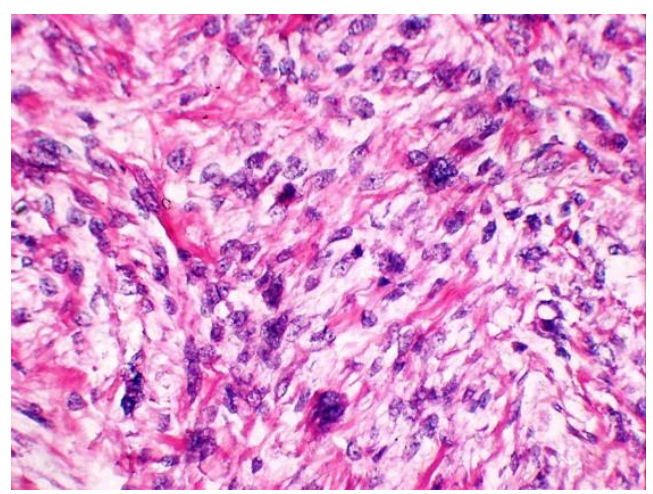

Fig. 5:

\section{Discussion}

Phyllodes tumor is a rare entity constituting less than $1 \%$ of all breast tumors. ${ }^{1-3}$ Initially, it was designated as cystosarcoma phyllodes in 1838 by Johannes Muller.' 'Sarcoma' is a Greek word which means flesh like and 'phyllon' means leaf like. It commonly occurs in women between 40 to 50 years. ${ }^{4,5}$ It has also been reported in males suffering from gynaecomastia. However in this study, all the patients were females with age range from 18 to 60 years.

Clinically, it's size varies from very small to huge lump upto $20 \mathrm{cms}^{10}$ but in our study, it is upto $40 \mathrm{cms}$. It is a benign breast lesion with history of rapid growth. ${ }^{11,12}$ Skin subjacent to the tumor shows bluish hue and prominent veins especially in case of large tumor but the retraction of nipple is usually not seen. Fixation to overlying skin and underlying pectoralis muscles is seen only in few cases. ${ }^{13}$ More frequently, it involves the upper and outer quadrant of the breast and can occur in either breast ${ }^{13,14}$. Tumor grows in the stroma, not from the ducts and lobules. Axillary lymph nodes may be palpable in about $10-15 \%$ of the cases, but only less than $1 \%$ patients had positive lymph nodes. ${ }^{15}$ None of the patient in this study had lymph node involvement.

As fibroadenoma and phyllodes tumor bear a morphologic resemblance to each other having in common stromal and epithelial component both, their diagnosis on cytology is difficult. However the mainstay for cytological diagnosis are hypercellular cohesive stroma, isolated stromal cells with bare nuclei, atypia of stromal cells, blood vessels traversing the stromal fragments and the absence of apocrine metaplasia. ${ }^{8}$ Stromal cells in the aspiration cytology smears are more in number in comparision to ductal epithelial cells. But the diagnostic accuracy of FNAC varies depending on the site of aspiration. The diagnostic hypercellular stroma may not be present if the sampling site is myxoid area or relatively hypocellular area. ${ }^{8}$ It is because of this, core biopsy is gaining importance as an alternative to cytology as it provides architectural information as compared to FNAC. Indication for core biopsy includes rapid 
increase in size, lump more than $3 \mathrm{cms}$ in diameter, in patients age more than 35 years, hypercellular stroma or indeterminate features on cytology. ${ }^{8}$ It this study diagnostic accuracy was $71 \%$. It depends upon the adequacy of sample as phyllodes tumors are known for their heterogenous nature. Various studies state that role of FNAC to diagnose phyllodes tumor is debatable showing accuracy of about $63 \%$. $^{16,17}$

On histopathological examination, grossly most of the small phyllodes tumors have lobulated surface and are white in color resembling fibroadenoma but the large tumors on cut show leaf like clefting spaces and "meaty" consistency because of areas of hemorrhage and necrosis. ${ }^{1}$ On microscopic examination also, phyllodes tumor resembles intracanalicular type of fibroadenoma because of it's exaggerated intracanalicular pattern and elongated ducts and papillary stromal protrusion which are lined by epithelium giving rise to leaf like fronds to the naked eye. It is differentiated from fibroadenoma by its stromal overgrowth and cellularity and the presence of mitotic activity. ${ }^{8}$ The stromal cellularity may be increased in juvenile fibroadenoma making the diagnosis of phyllodes tough but it is relatively uniform in fibroadenoma while in phyllodes, stromal cellularity is more pronounced in areas around the ducts (known as stromal heterogeneity) which is very important distinguishing feature. ${ }^{8}$

Regarding the distribution on histology, benign tumors are more frequent ${ }^{18}$ but in this study, borderline tumors were more common. Risk of local recurrence correlate poorly with histology, though the recurrence is more common with the borderline and the malignant phyllodes as compared to benign phyllodes. ${ }^{18}$ In present study, recurrence was seen with benign and borderline phyllodes. There is no reliable prognostic factor that can predict the metastasis or local recurrence but it is more common in borderline and malignant phyllodes to have distant metastasis. Size of the tumor is an important factor to predict the metastasis. There are various histologic prognostic factors that have been studied like presence of stromal overgrowth, infiltrative tumor margins, tumor necrosis, good mitotic activity and atypia of stromal cells. These important factors predict the recurrence but each factor has a very low predictive value in isolation. The most strong and independent factor for local tumor recurrence is the excised surgical margin, however there is no uniform consensus about the appropriateness of the excised margin to reduce the risk of recurrence. According to some studies, tumor margin width should be atleast 10 $\mathrm{mm}$. Overall, phyllodes tumor metastasizes in about $10 \%$ cases and it is more frequent in malignant phyllodes accounting approximately $20 \%$ cases. ${ }^{19}$ Most common sites for distant metastasis are lungs $(66 \%)$, bones $(28 \%)$ and the brain (9\%). That's why, it is necessary to diagnose malignant phyllodes tumor from diagnostic and treatment perspective so that these tumors can be adequately treated as tumors have risk of recurrence \& metastasis.

\section{Conclusion}

Phyllodes tumors are the rare breast tumors with unpredictable risk of metastasis and recurrence. It's histological categorization into benign, borderline and the malignant is problematic in few cases and it does not correlate well with biological behavior of the tumor. Phyllodes tumors bear resemblance to fibroadenoma and the distinction between the two is quite difficult. The treatment for phyllodes tumor remains the breast conservative surgery with adequate surgical margins.

\section{Funding: No funding sources Conflict of Interest: None declared Ethical Approval: Not required}

\section{References}

1. Dyer NH, Bridger JE, Taylor RS. Cystosarcoma phylloides. Br J Surg 1966;53:450-5.

2. Popescu I, Serbanescu M, Ivaschescu C. Phyllodes tumours of the breast. Zentbl Chir 1991;116:327-36.

3. Buchanan ED. Cystosarcoma phyllodes and its surgical management. Am Surg 1995;61:350-5.

4. Reinfuss M, Mitus J, Duka K, Stelmach A, Rys J, Smolak $\mathrm{K}$. The treatment and prognosis of patients with phyllodes tumor of the breast: an analysis of 170 cases. Cancer 1996;77(5):910-6

5. Salvadori B, Cusumano F, Del Bo R, et al. Surgical treatment of phyllodes tumors of the breast. Cancer 1989:63(12):2532-6.

6. Lakhani SR, Ellis IO, schnitt SJ, Tan PH, van de Vijver MJ, eds. World Health Organization Classification of Tumors of the Breast. Lyon, France: IARC;2012. World Health Organization Classification of Tumors; vol 4.

7. A.K. El-Naggar, B.Mackay, N.Sneige and J.G. Batsakis. "Stromal neoplasms of the breast: a comparative flow cytometric study," Journal of Surgical Oncology, vol.44, no.3,pp.151-156,1990.

8. R.K. Jaklin, P.F. Ridgway, P.Ziprin, V.Healy, D. Hadjiminas, and A.Darzi, "Optimising preoperative diagnosis in phyllodes tumor of the breast," Journal of Clinical Pathology, vol.59, no.5,pp.454-459,2006.

9. Fiks A. Cystosarcoma phyllodes of the mammary glandmuller's tumor. Virchows Arch A Pathol Anat Histo. 1981(1);392:1-6.

10. S.J. Parker, SA Harries- Phyllodes tumors, Postgrad Med J 2001;77:428-435.

11. Umpleby HC, Guyer PB, Moore I, et al. An evaluation of the preoperative diagnosis and management of cystosarcoma phyllodes. Ann R Coll Surg Engl 1989;71:285-8.

12. Bartoli C, Zurrida S, Veronesi P, et al. Small sized phyllodes tumor of the breast. Eur J Surg Oncol 1990;16:215-19.

13. Chua CL, Thomas A, Ng BK. Cystosarcoma phyllodes: a review of surgical options. Surgery 1989;105:141-7.

14. Stebbing JF, Nash AG. Diagnosis and management of phyllodes tumor of the breast: experience of 33 cases at a specialist centre. Ann R Coll Surg Engl 1995;77:181-4.

15. T.-C. Chao, Y.- F. Lo, S.- C. Chen, and M.- F. Chen, "Sonographic features of phyllodes tumors of the breast", 
Ultrasound in Obstetrics and Gynecology vol. 20, no. 1, pp. 64-71, 2002.

16. D.C.Chheing, J.F. Cangiarella, J.Waisman et al., "Fineneedle aspiration cytology of spindle cell lesions of the breast," Cancer, vol.87,pp.359-371,1999.

17. U. Simi, D. Moretti, P. Iacconi et al., "Fine needle aspiration cytopathology of phyllodes tumor. Differential diagnosis with fibroadenoma," Acta Cytologica, vol. 32, no.1, pp. 63-66, 1988.

18. G. Spitaleri et al. Critical Reviews in Oncology/ Haematology 88(2013) 427-436.

19. Moffat CJC, Pinder SE, Dixon AR, et al. Phyllodes tumor of the breast: A clinicopathological review of the thirtytwo cases. Histopathology 1995;27:205-18. 